\title{
Neuroprotective compounds and innovative therapeutic strategies for Parkinson's disease: experimental and clinical studies
}

This article was published in the following Dove Press journal:

Open Access Journal of Clinical Trials

29 September 2009

Number of times this article has been viewed

\author{
Fabio Blandini \\ Interdepartmental Research Center \\ for Parkinson's Disease (CRIMP), \\ IRCCS Neurological Institute \\ "C. Mondino Foundation", \\ Pavia, Italy
}

Correspondence: Fabio Blandini Interdepartmental Research Center for Parkinson's Disease (CRIMP), IRCCS Neurological Institute C. Mondino Via Mondino 2, 27I00 Pavia, Italy

Tel +390382 380416

Fax +390382380448

Email fabio.blandini@mondino.it

\begin{abstract}
Identifying new therapeutic strategies capable of modifying the course of Parkinson's disease (PD) is currently one of the major goals for the researchers of this field. Various mechanistic definitions have been proposed to describe the hypothetical ability of a therapeutic intervention to prevent, block or reverse the neurodegenerative process underlying PD. The general term "neuroprotection" has been related to the capacity of interfering with the ongoing process of neuronal cell death, in order to slow or halt disease progression, while a term such as "neurorestoration" would apply to any intervention capable of increasing the number of surviving dopaminergic neurons. Although none of the therapeutic approaches tested in PD patients has so far shown the ability to stop or reverse disease progression, a certain degree of neuroprotection can be achieved with compounds that are already available in the pharmacological armamentarium of the neurologist. Treatment with dopamine agonists or MAO-B inhibitors, particularly when started in the very early phases of the disease, may play disease-modifying effects and even L-DOPA, at low doses, may be slightly neuroprotective. For a true neurorestorative intervention, promising perspectives are being provided by neurotrophic factors and stem cells, which, however, still need to unveil their full potential.
\end{abstract}

Keywords: L-DOPA, dopamine agonists, MAO-B inhibitors, trophic factors, stem cells

\section{Parkinson's disease: general concepts and pathogenic hypotheses}

Parkinson's disease (PD) is the second most common neurodegenerative disease in the general population, with a prevalence of $1 \%$, at the age of 65 that tends to increase dramatically with aging. ${ }^{1}$ In the setting of an aging population, the social cost of this condition is destined to increase, thereby increasing the social relevance of the disease. In the United States, for example, the annual cost of PD has been estimated at US $\$ 10.8$ billion/year. ${ }^{2}$ There is, therefore, a pressing need to clarify various aspects of PD pathogenesis and pathophysiology that are still elusive, in order to devise innovative therapeutic strategies.

Idiopathic PD is a multi-system, complex disorder with an uncertain etiology, characterized by the involvement of selected neuronal populations throughout the central and peripheral nervous systems. ${ }^{3,4}$ The pathological hallmark of the disease is degeneration of dopaminergic, melanized neurons of the substantia nigra pars compacta (SNc) projecting to the striatum; striatal dopaminergic denervation then triggers complex functional modifications within the basal ganglia circuitry, which cause the typical motor symptoms of the disease (tremor, rigidity, bradykinesia). ${ }^{5}$ submit your manuscript | www.dovepress.com

Dovepress 
Other neurotransmitter systems are also involved in the disease, including noradrenergic, serotonergic and cholinergic systems. ${ }^{6}$ Although PD is the prototypical movement disorder, the disease is also characterized by numerous non-motor symptoms, which include autonomic dysfunction, sleep disorders, psychiatric symptoms, gastrointestinal dysfunction and cognitive dysfunction. ${ }^{7}$

\section{PD pathogenesis}

As mentioned above, the pathological signature of PD is the degeneration of SNc neurons, associated with the presence of intracytoplasmic, proteinaceous inclusions, termed Lewy bodies (LBs). LBs are spherical, eosinophilic structures with a central, granular core surrounded by a fibrillary halo. The major proteic component of LBs is $\alpha$-synuclein, but numerous other proteins are present in the LB, including ubiquitin, parkin, torsin A, synphilin-1, neurofilaments, and heat shock proteins. ${ }^{8}$

The primary cause of the degenerative process underlying PD remains unknown. No single causative factor has yet been identified for the sporadic form of the disease, which represents the vast majority of PD cases. Indeed, due to the multi-factorial nature of the disease, the process leading to nigral cell death is likely to originate from the reciprocal interactions of a restricted number of potentially contributing mechanisms (Figure 1) including mitochondrial defects, enhanced formation of reactive oxygen species leading to oxidative damage and aberrant protein aggregation. ${ }^{9}$ The latter may be linked to reduced efficiency of the ubiquitin-proteasome system, an intracellular mechanism specifically devoted to the degradation of altered proteins, whose involvement in PD pathogenesis has been repeatedly suggested. ${ }^{10}$ The combined actions of these phenomena may disrupt the physiological dynamics of apoptosis within the $\mathrm{SNc}$, thus triggering uncontrolled neuronal death. An additional contribution may originate from the neuroinflammatory response, mostly sustained by microglial activation, which accompanies and, to a certain extent, promotes the progressive damage of the nigrostriatal pathway. ${ }^{11,12}$

Defective regulation of apoptosis may, indeed, play a central role in the process of nigral cell loss. ${ }^{13}$ As opposed to necrosis, apoptosis is an active process triggered by the activation of specific cellular mechanisms and evolving through a series of defined steps. ${ }^{14}$ Apoptosis can be triggered by numerous factors, some of which have been implicated in PD pathogenesis, such as impaired activity of mitochondrial enzyme complex $\mathrm{I},{ }^{15}$ excessive stimulation of glutamate receptors ${ }^{16}$ or proteasomal impairment. ${ }^{17,18}$

\section{PARKINSON'S DISEASE}

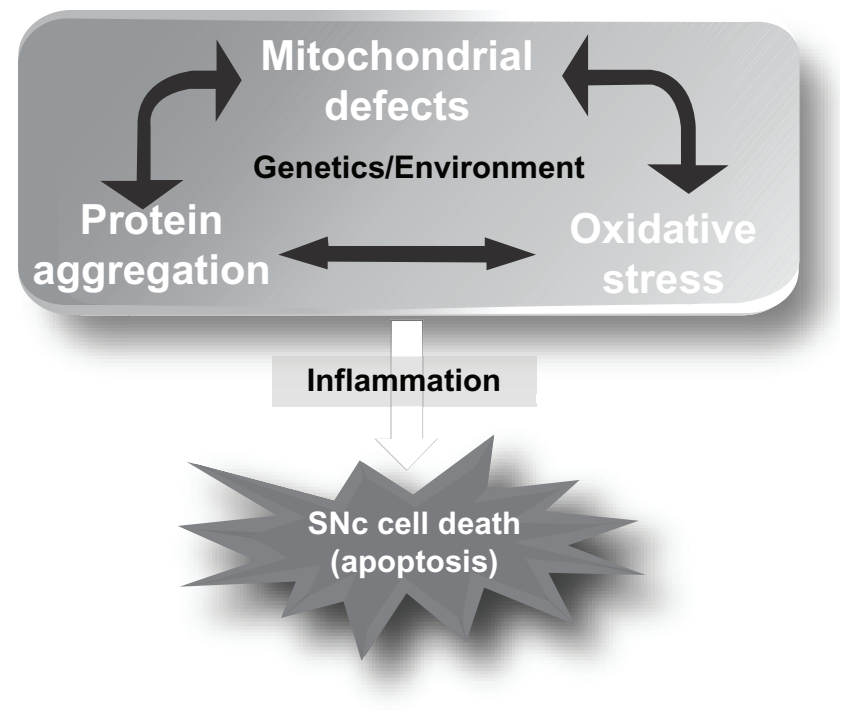

Figure I Factors that may contribute to the pathogenesis of Parkinson's disease. Mitochondrial defects, oxidative stress and protein aggregation due to cell protein mishandling are all mechanisms involved in the generation of the nigrostriatal damage. Their action is superimposed over a favorable background where genetic and environmental factors play a central role. By interacting with each other, these mechanisms may trigger cell death in the substantia nigra pars compacta $(\mathrm{SNc})$, possibly by apoptosis. Neuronal death is accompanied, and probably sustained, by neuroinflammatory reaction. All these mechanisms are potential targets for neuroprotective interventions.

Signs of apoptotic cell death, ${ }^{19,20}$ increased levels of apoptosis effectors caspase- 3 and caspase- 8 and of pro-apoptotic protein Bax, ${ }^{21-24}$ along with up-regulation of anti-apoptotic protein Bcl-2, ${ }^{25,26}$ have been detected in the SNc of PD patients. Pro-apoptotic changes, along with reduced proteasomal activity, have also been reported in peripheral cells of PD patients. ${ }^{27-29}$ The role of apoptosis in $\mathrm{PD}$ pathogenesis is further supported by the fact that two toxins routinely used to replicate PD features in animals, such as 1-methyl-4-phenyl-1,2,3,6-tetrahydropyridine (MPTP) and 6-hydroxydopamine (6-OHDA), cause nigral degeneration by triggering the apoptotic cascade. ${ }^{30}$

\section{PD treatment: current strategies and future perspectives}

Although 4 decades have passed since its use was proposed for PD treatment, ${ }^{31}$ replacement of deficient dopamine with its direct precursor, L-3,4-dihydroxyphenylalanine (L-DOPA), is still the most effective and commonly prescribed treatment for PD. Unlike dopamine, L-DOPA readily crosses the blood-brain barrier; once in the brain, the drug is converted into dopamine by aromatic-L-amino-acid decarboxylase, which is enriched in nigrostriatal terminals. Newly synthesized dopamine is stored in the terminals and 
then released, stimulating post-synaptic dopamine receptors and mediating the anti-parkinsonian effects of L-DOPA. To avoid peripheral catabolism of L-DOPA, which would reduce drug's efficacy, peripheral decarboxylase inhibitors, such as carbidopa or benserazide, are associated in the same formulation with L-DOPA. ${ }^{32,33}$

Unfortunately, long-term treatment with L-DOPA is associated with the occurrence of numerous complications, extremely bothersome for the patient, such as "on-off" fluctuations, freezing episodes, lack of responsiveness ("wearing off") and abnormal, uncontrollable movements known as dyskinesias. ${ }^{34}$ This is a phenomenon of considerable proportion, particularly when high dosages of L-DOPA are used. In fact, if L-DOPA-induced dyskinesia (LID) develops in approximately $50 \%$ of the PD patients treated with low doses of the drug, the percentage approaches $90 \%$ when patients are treated with maximally tolerated doses. ${ }^{35,36}$ Moreover, frequency and severity of LID increase as the disease and duration of the pharmacological treatment proceed.

LID represents the main drawback of L-DOPA treatment and the search for alternative therapeutic tools is currently a major challenge for the researchers in the PD field. This has led, for example, to the development of a surgical approach to PD treatment based on electrical stimulation, at high frequency, of the subthalamic nucleus (deep brain stimulation or DBS); ${ }^{37}$ subthalamic nucleus is the only excitatory (glutamatergic) nucleus of the basal ganglia circuitry and becomes pathologically overactive in PD patients. ${ }^{5}$ The procedure has represented a major breakthrough in the PD research of the past two decades and is now established as a main therapeutic option for the disease, at least in selected groups of PD patients. Thanks to the beneficial effects of DBS on PD symptoms, operated patients can considerably reduce their daily intake of L-DOPA, thereby limiting the prodyskinetic effects of the drug. Description of the procedure goes beyond the scope of this paper; for a comprehensive an updated overview, see the recent review published by the group of Benabid. ${ }^{38}$

Another major limitation of L-DOPA is that the drug counteracts PD motor symptoms - at least for a certain period of time - without affecting progression of the disease, which continues to evolve synchronous with the degeneration of residual nigrostriatal neurons. This latter consideration has prompted extensive investigation, both at the pre-clinical and clinical level, to identify new therapeutic strategies capable of modifying PD course by exerting neuroprotective effects. This is, currently, the major goal for PD research.

\section{Neuroprotection, neurorestoration, or neuroregeneration?}

Various, mechanistic definitions have been proposed to describe the ability of a hypothetical therapeutic intervention to prevent, block or reverse the neurodegenerative process underlying PD. The general term "neuroprotection", for example, has been related to the capacity of interfering with the ongoing process of neuronal cell death, in order to slow or halt disease progression, while the concept of "neurorescue" would imply recovering dying neurones by reversing established metabolic abnormalities; a third term, "neurorestoration" would apply to any technique aimed at increasing the number of surviving dopaminergic neurones. ${ }^{39,40}$

More recently, the more comprehensive term diseasemodifying has become quite popular, probably because it gives a better idea of what a new drug should do: modifying, that is, slowing, stopping or reversing the natural course of the disease, regardless of the underlying mechanism.

\section{Neuroprotective potential of drugs already in use for PD treatment}

Various studies conducted in the last 10 to 15 years have addressed this point, with controversial results, particularly for the dopaminergic agents. This part of the review will discuss the main findings obtained by experimental and clinical studies conducted to investigate whether L-DOPA, dopamine agonists and monoamine oxidase (MAO) inhibitors are capable of modifying PD progression.

\section{L-DOPA}

L-DOPA has been repeatedly "accused" of being cytotoxic; potential neurotoxicity of L-DOPA has, in fact, fueled a wide debate in the late 1990s, supported by numerous experimental studies.

Experimental data Various studies, mostly conducted in vitro, have proposed that L-DOPA can cause cell death, due to its pro-oxidant properties. ${ }^{41-43}$ However, there is little experimental evidence supporting L-DOPA neurotoxicity in vivo; in fact, other studies have proposed that L-DOPA toxicity takes place only at extremely high concentrations, virtually impossible to reach in the patient, while - on the contrary - low concentrations of the drug may exert neuroprotective effects. ${ }^{44-47}$ There is evidence, for example, that dopamine receptors are linked to trophic receptors, so that that dopamine derived from L-DOPA may activate the PI-3 kinase/ Akt antiapoptotic pathway, ${ }^{48}$ thereby promoting neuronal survival. In a recent study conducted on PC12 cells, ${ }^{49}$ 
the authors showed that L-DOPA can improve cell viability and reduce spontaneous apoptosis for concentrations up to $20 \mu \mathrm{M}$. Apoptotic cell death is, then, triggered when higher concentrations are used. Also in this case, specific kinases may play a central role, since the same authors showed that high concentrations of L-DOPA activate glycogen synthase kinase-3 (GSK-3), a key regulatory kinase that intervenes in a number of critical biological neuronal functions, including gene expression, cellular architecture, neuronal cell death and inflammation. ${ }^{50}$ Inhibition of GSK-3 blocks cytotoxicity associated with high L-DOPA concentrations.

Clinical data To establish whether treatment with L-DOPA can influence disease progression, particularly when started in the early phase of PD, a multicenter, double-blind, randomized, controlled clinical trial (ELLDOPA) was conducted at 38 sites in the United States and Canada. ${ }^{51,52}$ Three hundred and sixty-one patients with early $\operatorname{PD}(<2$ years' duration, not requiring symptomatic therapy) were enrolled and randomly assigned to treatment with L-DOPA (150, 300 or $600 \mathrm{mg} /$ day) or placebo. Treatment was maintained for 40 weeks, then suspended for 2 weeks, with the final assessment of PD severity being made at week 42. In a subgroup of 142 subjects, imaging of striatal (123)iodine 2-beta-carboxymethoxy-3beta-(4-iodophe nyl)tropane (beta-CIT) uptake at baseline and at week 40 was also conducted, to have a functional measure of the loss of dopaminergic terminals associated with PD. Results of the study were controversial: treated patients showed better scores at the Unified Parkinson's Disease Rating Scale (UPDRS) than those in the placebo group, at the end of the study, notwithstanding the two-week discontinuation of L-DOPA. This led the authors to propose that L-DOPA does not hasten - or may even slow - the progression of $\mathrm{PD}$, although it is possible that long duration effects of the drug are not completely eliminated after 2 weeks of washout. If this was the case, the effect would be merely related to the symptomatic efficacy of L-DOPA. At odd with the clinical findings, the beta-CIT study showed that L-DOPA, particularly at the highest dose (600 mg/day), was associated with a faster rate of decline in this marker of nigrostriatal function, compared to placebo. This would support the view that L-DOPA might indeed be toxic to nigrostriatal neurons; however, it is also possible that the drug may interfere with the expression of the dopamine transporter, at the striatal level..$^{53}$

The issue of the long-term effects of L-DOPA on PD remains, therefore, controversial. However, the concern about the potential neurotoxicity of the compound, at least in the clinical setting, has been considerably reduced, if not completely overcome.

\section{Dopamine agonists}

Dopamine agonists are widely used in the treatment PD patients, particularly in the early phases of the disease. Compared to L-DOPA, which produces discontinuous stimulation of dopamine receptors due to its pulsatile pharmacokinetic profile, dopamine agonists have a much longer plasma half-life; this results in a more continuous dopaminergic stimulus, thereby reducing the risk of motor complications. Dopamine agonists have been, therefore, proposed as a first-line treatment for PD. ${ }^{54}$

Experimental data The view that dopamine agonists should be used since the earlier phase of PD has been influenced by the hypothesis that this class of drugs may exert neuroprotective effects. Considerable experimental evidence has been produced, supporting this view and proposing multiple mechanisms by which dopamine agonists might protect neuronal cells against various types of cytotoxic stimuli. Some of these mechanisms are mediated by the stimulation of dopamine receptors, while others appear to be independent of receptor stimulation.

A major mechanism that has been considered, particularly in the earlier studies, is the antioxidant efficacy of this class of drugs, which seems to depend on their hydroxylated benzyl ring structure, which gives them the ability to scavenge reactive oxygen species. This has been shown in numerous studies conducted in animal models, where dopamine agonists proved able to counteract the neuronal damage caused by powerful pro-oxidant neurotoxins, such as MPP+, 6-OHDA, nitric oxide or malonate. ${ }^{55-60}$ Dopamine agonists have also shown anti-apoptotic properties; in vitro findings, for example, showed that pramipexole reduces cell death by counteracting the mitochondrial phase of apoptosis in dopaminergic cells exposed to MPP+ or rotenone, ${ }^{61,62}$ the same drug has shown protective effects in the MPTP primate model of $\mathrm{PD}^{63}$ and, more recently, against the nigral degeneration induced by local administration of lypopolysaccharide. ${ }^{64}$

Other mechanisms have been recently identified, which may explain the neuroprotection granted, at least in experimental models, by this class of compounds. For example, it has been suggested that dopamine agonists may interact with selected, regulatory kinases, such as Akt and GSK-3, which play a crucial role in various cellular mechanisms, including inflammation and cell death. ${ }^{65}$ It has also been suggested that dopamine agonists, this time by acting on D3 receptors, 
may have growth factor-like properties by inducing upregulation of brain derived neurotrophic factor (BDNF) and glial cell-derived neurotrophic factor (GDNF). ${ }^{66}$

Clinical data The neuroprotective potential of dopamine agonists has been tested in clinical trials, using neuroimaging techniques to investigate whether treatment with these compounds is able to counteract the degeneration of nigrostriatal terminals. In the REAL-PET study, ropinirole was compared with L-DOPA using PET imaging to study the striatal uptake of fluorodopa, ${ }^{67}$ the study demonstrated a $34 \%$ reduction in the progression of the signal loss, over 2 years, in patients treated with ropinirole compared with those on L-DOPA. Analogously, the CALM-PD-CIT study compared pramipexole to levodopa using beta-CIT SPECT beta-CIT to follow the rate of loss of dopamine transporter, at the striatal level, over a 4 -year period; ${ }^{68}$ at all the established time points, the pramipexole group showed a significant reduction in the rate of transporter loss, with an average difference, compared to the L-DOPA group, of $36 \%$. Therefore, both studies demonstrated that prolonged treatment with dopamine agonists is associated with a slower decline of imaging biomarkers of nigrostriatal function; these results seemed to support the protective effects of dopamine agonists or, as an alternative, the toxicity of L-DOPA to dopaminergic neurons. However, it has also been suggested that dopamine agonists and L-DOPA may have different pharmacological effects on either fluorodopa uptake or expression of the dopamine transporter, thereby making the interpretation of these results more complex..$^{53}$ Moreover, a recent paper by the Parkinson Study Group has shown that, 6 years later, patients of the CALM-PD-CIT study treated with initial pramipexole or initial levodopa show similar levels of self-reported disability. ${ }^{69}$ These findings led the authors to conclude that, in the long-term, "there is no strong evidence favoring either of these initial treatment strategies over the other". This also points out the difficulty to confirm neuroprotection in clinical trials. The adoption of a novel trial design like the "delayed-start", repeatedly used to test the disease-modifying effects of rasagiline (see below), may be useful to re-evaluate the neuroprotective potential of dopamine agonists or, more in general, of drugs previously thought to provide neuroprotection in PD.

\section{MAO-B inhibitors}

Inhibitors of monoamine oxidase (MAO) B have attracted the interest of neuroscientists in recent years, mostly because of the potential role this enzyme would play in the mechanisms that sustain the nigrostriatal damage in PD (see below). Two MAO-B inhibitors are currently used in PD, particularly in the early phase of the disease because of their putative neuroprotective effects: selegiline and, more recently, rasagiline.

MAO, which is present in two forms (MAO-A and MAO-B), is mainly responsible for the oxidative deamination of monoaminergic neurotransmitters, including noradrenaline, serotonin and dopamine. As such, the enzyme plays a central role in neurotransmission within the central nervous system. Noradrenaline and serotonin are preferentially metabolized by MAO-A, while dopamine is a substrate for both forms. ${ }^{70} \mathrm{MAO}-\mathrm{B}$ is the predominant form in the brain and is relatively abundant within the human basal ganglia nuclei. ${ }^{71}$ In the 1970 s, the theoretical possibility of potentiating dopaminergic transmission by inhibiting dopamine metabolism raised great interest in the use of MAO inhibitors, originally developed to treat depression, for PD therapy. However, the use of non-selective agents was associated with the risk of hypertensive crisis caused by the peripheral inhibition of MAO-A and the subsequent potentiation of cardiovascular tyramine effects with the ingestion of high tyramine-containing foods, such as aged cheese and red wine. To avoid this harmful reaction, selective inhibitors of MAO-B were developed; this led to the synthesis of selegiline, a propargyl-derived compound, structurally related to pargyline and clorgyline, but provided with the ability to block, selectively and irreversibly, the activity of MAO-B.

\section{Selegiline}

The availability of such an agent prompted various studies on the symptomatic efficacy of this pharmacological approach to PD therapy. At the same time, it became clear that, at least theoretically, MAO-B inhibition could also have neuroprotective effects. The SNc is exposed to higher levels of oxidative stress relative to other areas of the brain, for reasons that include auto-oxidation of melanin, presence of high levels of iron, and, more importantly for PD, oxidative catabolism of dopamine by MAO-B. These factors contribute to a high rate of reactive oxygen species formation, which is likely enhanced in PD patients. ${ }^{72}$

Experimental data The role of MAO-B in PD pathogenesis was further suggested when the mechanism underlying neurotoxicity of MPTP (1-methyl-4-phenyl-1, 2,3,6-tetrahydropiridine) was clarified. It was demonstrated that MPTP, which can induce a PD-like syndrome in humans 
and primates is, in fact, a pro-toxin that requires oxidative deamination by MAO-B to transform into the active toxin 1-methyl-4-phenylpyridinium (MPP+). ${ }^{73}$ It was, therefore, suggested MAO-B inhibition may protect nigral neurons from exogenous agents requiring this enzymatic step to fully express their neurotoxicity. Various in vitro and in vivo studies have supported this hypothesis, showing that selegiline can be neuroprotective against MPTP and MPP+, by reducing the rate of free radical formation and prompting the activation of anti-apoptotic mechanisms. ${ }^{74-77}$

Clinical data The possibility that blocking MAO-B activity may modify PD progression, in patients, was verified in the DATATOP study, in which efficacy of selegiline and vitamin E supplementation were tested, ${ }^{78,79}$ as well as in subsequent studies. ${ }^{80}$ Unlike vitamin E, selegiline was shown to delay, significantly, the need for L-DOPA in untreated PD patients, with respect to placebo. However, it was not possible to determine whether the positive results observed in the selegiline group were due to a protective effect of the drug against the ongoing neurodegeneration, or to the potentiating effects on dopaminergic transmission, which would account for the mild symptomatic effects of the drug. In fact, selegiline slowed developing disability by ameliorating the motor impairment, as measured at the UPDRS, in the early phases of treatment in otherwise untreated PD patients; the advantage over placebo, however, tended to fade with time or after wash-out, further supporting a prevalent symptomatic effect of the compound. ${ }^{81}$ The notion, acquired later, that selegiline is metabolized into L-methamphetamine ${ }^{82}$ led various authors to suggest that transformation into such a neurotoxic molecule may, indeed, reduce the neuroprotective potential of selegiline. ${ }^{83-85}$

In a subsequent study designed to resolve these issues, the SINDEPAR study, patients with untreated PD were randomized to selegiline or placebo; rate of change in UPDRS scores between baseline evaluation and a final evaluation performed 2 months after treatment withdrawal was the endpoint of the study. Also in this case, although patients treated with selegiline showed a less steep decline in the UPDRS score, it remained unclear whether this was due to a protective effect or to a long-duration symptomatic effect of selegiline. ${ }^{86}$

\section{Rasagiline}

Rasagiline [R(+)-N-propargyl-1-aminoindan] is structurally related to selegiline, but considerably more potent and, unlike selegiline, is not metabolized to amphetamine and/or methamphetamine. ${ }^{87,88}$
Experimental studies Numerous in vitro and in vivo studies have shown that rasagiline possesses neuroprotective properties. In vitro, the drug counteracts the pro-apoptotic effects of various toxins, such as N-methyl(R)salsolinol, 6-OHDA and peroxynitrite. ${ }^{89,90}$ Rasagiline also increased survival in models based on alternative cytotoxic insults, such as oxygen and glucose deprivation in differentiated PC12 cells. ${ }^{91}$ Subsequent studies have shown that rasagiline can prevent cell death by interfering with various steps of the apoptotic cascade, including activation of caspase 3 and poly (ADP-ribose) polymerase-1 (PARP-1), translocation of glyceraldehyde-3-phosphate dehydrogenase (GADPH) and nucleosomal DNA fragmentation; the drug is also able to induce the expression of anti-apoptotic proteins Bcl-2 and Bcl-xL, while down-regulating pro-apoptotic Bad and Bax proteins. ${ }^{92-94}$ The mitochondrial phase of apoptosis, in particular, seems to be a specific target for the pro-survival effect of rasagiline. In neuroblastoma cells, rasagiline prevents the swelling of mitochondria and loss of mitochondrial membrane potential elicited by pro-apoptotic toxin $N$-methyl$R$-salsolinol. ${ }^{95,96}$ Rasagiline is also able to activate protein kinase $\mathrm{C}(\mathrm{PKC}),{ }^{97}$ which exerts a protective effect on neuronal cells, ${ }^{98,99}$ as well as to increase the expression of GDNF through the activation of nuclear transcription factor NF-kB. ${ }^{100}$

These effects are unrelated to the inhibitory effect of rasagiline on MAO-B, as similar neuroprotective effects have been obtained with the S-isomer of rasagiline (TVP 1022), which is 1000 times less active, as a MAO inhibitor, than rasagiline. ${ }^{101}$ Neuroprotection by rasagiline has been demonstrated also in animal models of PD, in which the drug proved able to counteract nigrostriatal damage caused by administration of specific toxins, such as MPTP or 6-OHDA. ${ }^{102,103}$

Clinical data In recent years, considerable evidence has accumulated on the efficacy of rasagiline in the treatment of PD, either as monotherapy or adjunct therapy to L-DOPA. ${ }^{104,105}$ In 2002, the Parkinson Study Group published the results of a 26-week, placebo-controlled investigation of rasagiline treatment in patients with early PD. ${ }^{106}$ The study - termed TEMPO - was a double-blind, placebo-controlled, clinical trial that included over 400 subjects. Results showed that, compared to placebo (in which UPDRS scores deteriorated), UPDRS scores of patients taking rasagiline tended to stabilize. The idea that rasagiline may, indeed, modify the progression of the disease was suggested by the second part of the TEMPO study, which was designed to assess whether earlier initiation of rasagiline treatment resulted in better clinical response than delayed initiation. ${ }^{107}$ A “delayed-start" design was used, which 
was developed, as an alternative to the trial designs previously used, to avoid misinterpretation of the results due to the symptomatic effects of the compound being tested. According to this innovative trial design, subjects were randomized to receive rasagiline for 12 months or placebo for the first 6 months, followed by rasagiline for the remaining 6 months. The results showed that the beneficial effect of rasagiline was more pronounced in patients treated with the drug from the start, as opposed to those initially treated with placebo. This finding, which cannot be entirely explained by symptomatic activity of rasagiline, suggested that rasagiline may, indeed, have a "disease-modifying" effect. Interestingly, a subsequent study designed to analyze the long-term follow-up of these patients showed that the advantage gained by those treated with rasagiline from the beginning, in terms of slower disease progression, was maintained for up to 5.5 years from the end of the TEMPO trial. ${ }^{108}$

More recently, another multicenter, double-blind, placebo-controlled, study (ADAGIO) has been conducted in almost 1,200 early untreated PD patients, to further substantiate the disease-modifying properties of rasagiline. The delayed-start design was used also in this case, but with a longer study duration (18 months) compared to TEMPO. Patients were randomized to receive rasagiline (1 or $2 \mathrm{mg}$ per day) or placebo for 9 months, after which, all patients were treated with rasagiline ( 1 or $2 \mathrm{mg}$ per day) for other 9 months. ${ }^{109}$ The main objective of the study was to detect significant divergence in the slopes of the change in UPDRS scores between patients treated with rasagiline from the start and patients who delayed the treatment. Preliminary results of the ADAGIO study ${ }^{110}$ suggest that PD tends to progress more slowly in patients treated with rasagiline $1 \mathrm{mg}$ per day; the degree of benefit - in terms of changes at the UPDRS score - is mild, although statistically significant: mean UPDRS change, from baseline to the end of the study, is reduced by 1.7 units in patients treated with rasagiline from the start, with respect to those treated with placebo for the first 9 months. The same beneficial effect is not seen with rasagiline $2 \mathrm{mg}$ per day. The reason of this difference between the two dosages is currently unclear.

\section{New perspectives: from neuronal transplantation to trophic factors and stem cells as potential tools for neurorestoration}

The pioneering experiences of almost 20 years ago, with the transplantation of fetal mesencephalic cells into the brain of
PD patients, ${ }^{111,112}$ prompted the idea that the damaged brain might be repaired. This led to numerous studies investigating, more in detail, the effects of transplanting immature dopaminergic neurons - of embryonic or fetal origin - into PD brains, with controversial results (see below).

The concept of neurorestoration has subsequently evolved, thanks to the new knowledge generated, leading to the view that the process of brain repairing may be triggered, substantially, via two different strategies, which may also be combined: a) promoting neuronal restoration via neurotrophic factors; b) replacing lost neurons with stem cells able to differentiate into dopaminergic neurons.

\section{Trophic factors}

The progressive nature of the loss of dopaminergic neurons that characterizes PD may favor strategies aimed at protecting neurons from cell death and promoting both growth and regeneration. This observation has prompted numerous experimental studies, with the objective of investigating the neuroprotective potential of various neurotrophic factors in animal models of PD.

Experimental data Initial studies tested the effect of the direct, intra-cerebral infusion of numerous factors, including epidermal growth factor, basic fibroblast growth factor, BDNF, neurturin (NTN), and GDNF, ${ }^{113-121}$ which showed variable degrees of neuroprotection. GDNF repeatedly proved the most potent and consistent agent in counteracting the effects of the neurotoxins used to reproduce PD-like pathology. ${ }^{122-124}$ Indeed, GDNF is crucial for the correct development and functionality of the nigrostriatal pathway and seems to play a central role in the resistance of neuronal cells to neurotoxic insults. ${ }^{125-127} \mathrm{SNc}$ neurons contain relatively low levels of GDNF compared to neurons of the adjacent ventral tegmental area, which - as a result - are far more resistant than $\mathrm{SNc}$ neurons to the neurotoxins used to replicate PD pathological features in animals. ${ }^{128}$

Further studies have used alternative strategies to grant continuous delivery of exogenous GDNF to the injured brain. For example, microspheres made of biocompatible, poly-lactic-co-glycolic acid polymer have been used; ${ }^{129-131}$ upon degradation, these microspheres release GDNF at the site of implantation in a controlled fashion that can last for several months. Using this technique, Gouhier et $\mathrm{al}^{132}$ have shown that GDNF-releasing microspheres, implanted simultaneously with an intrastriatal injection of 6-OHDA, protect dopaminergic neurons for up to 6 weeks. Analogously, it has been shown that implantation of 
GDNF-releasing spheres into the striatum of 6-OHDA lesioned rats promotes sprouting of dopaminergic fibers ${ }^{133}$ and long-term amelioration of motor dysfunction. ${ }^{134,135}$ Another method to deliver GDNF across the blood-brain barrier was described by Dietz et al ${ }^{136}$ who generated a fusion protein between the HIV-1-Tat-derived cell-penetrating peptide and GDNF. The authors tested the construct in MPTP-treated mice, showing that the Tat-GDNF fusion protein reached the dopaminergic neurons; however, no neuroprotective effects were observed.

The need to have a continuous supply of GDNF have led to the use of genetic engineering techniques, based on the adoption of viral vectors carrying the GDNF gene, which can induce local GDNF expression in the targeted tissue. Various viral vectors, including adenovirus, adeno-associated virus (AAV) and lentivirus have been tested in animal models of $\mathrm{PD} .{ }^{137}$ With the earlier generations of vectors, prolonged GDNF expression was associated with inflammatory reactions, due to the immunogenicity of the vectors, which implied limited safety and efficiency of the procedure. These problems have been overcome with the newest generations of recombinant viral vectors (AAV, in particular); these vectors currently represent the most efficient and reliable means to obtain a long-term gene expression following GDNF-transduction.

Using recombinant vectors carrying the GDNF gene, various groups have shown neuroprotection of nigrostriatal neurons against PD-inducing neurotoxins and motor recovery in lesioned animals ${ }^{138-142}$ following intrastriatal administration. In general, the procedure tends to be more effective when applied before the toxic insult is delivered; however, beneficial effects - including increased survival of SNc neurons and increased levels of striatal dopamine - have also been described when the GDNF gene-carrying vector is infused after the nigrostriatal lesion is established. ${ }^{143-145}$ Promising results have also been obtained with NTN, a member of the GDNF family; in a very recent paper, Herzog et al ${ }^{146}$ evaluated the long-term expression, bioactivity, and safety/tolerability of CERE-120, an adeno-associated virus type 2 vector encoding human NTN, in rhesus macaques. CERE-120 was delivered via bilateral, stereotaxic injection into the striatum and animals were monitored for 1 year. Long-term expression of NTN in the striatal tissue was coupled with increased immunolabeling for dopaminergic marker tyrosine hydroxylase (TH), in the striatum, and hypertrophy of dopaminergic cells in the SNc, without signs of neurological or systemic toxicity.
Other transgenic techniques devised to deliver exogenous GDNF to the brain have included the use of cells - such as bone marrow or neural stems cells or astrocytes - engineered to produce GDNF. These cells has proven effective in animal PD models when infused intravenously, ${ }^{147}$ or implanted into the striatum ${ }^{148}$ or into the $\mathrm{SNc}^{149,150}$ prior to the induction of the nigrostriatal lesion. In a variant of this approach, GDNF-releasing transgenic cells have been administered to lesioned animals after having been incorporated in microcapsules of biocompatible material; microcapsules were designed to allow inward diffusion of nutrients while allowing outward secretion of the trophic factors, thereby protecting the secreting cells from the host immune system and reducing the risk of rejection. Also in this case, positive results have been obtained in experimental PD models. ${ }^{151}$

Clinical data The positive results obtained in experimental studies have prompted the execution of clinical trials, to verify whether experimental findings could be translated into a concrete advantage for the PD patients. The results obtained so far have been controversial. In an initial study by Nutt et al, ${ }^{152}$ GDNF was injected into the lateral ventricle using a mechanical pump; no significant amelioration of PD symptoms was observed, while adverse GDNF-related effects, mostly represented by sensory symptoms (primarily paresthesias), were present. This led the authors to the conclusion that, although biologically active (as demonstrated by the adverse effects), GDNF may have not been effective because the site of injection was too distant from the striatum or SNc. On the contrary, positive results were obtained in two subsequent openlabel trials, in which GDNF was infused directly into the putamen. According to these findings, an improvement of PD symptoms could be obtained after either bilateral ${ }^{153}$ or unilateral, ${ }^{154}$ intra-putaminal infusion. At odd with these encouraging results, however, a double-blind, placebocontrolled study conducted by Lang et al ${ }^{155}$ failed to confirm the beneficial effects of the intrastriatal infusion of GDNF. It was also shown that PD patients were generating antibodies against GDNF, thereby making the issue of GDNF clinical trials extremely controversial.

A phase I, open-label clinical trial was conducted to assess the safety, tolerability, and potential efficacy of intraputaminal delivery of CERE-120 (NTN) in PD patients. ${ }^{156}$ The procedure proved safe, with no adverse events after 1 year, and well tolerated by patients. Significant improvements were seen in some, but not all, the clinical parameters measuring PD-related disability, such as the off-medication 
motor subscore of the UPDRS or the time spent in "on" condition without dyskinesia. No changes were observed in striatal ${ }^{18} \mathrm{~F}$-levodopa-uptake after treatment. These results, as the authors of this study point out, should be considered as preliminary until data from controlled clinical trials will be available. A phase II, double-blind, multicenter, controlled study on CERE-120 is, in fact, ongoing (NCT00400634; source: ClinicalTrial.Gov). The results of this study will clarify the actual efficacy of this therapeutic approach.

\section{From neuronal transplantation to stem cells}

The pioneering experiences with neural tissue transplantation of the late 1980s have generated further studies investigating, more in detail, the effects of transplanting immature dopaminergic neurons in animal models of PD and in PD patients.

\section{Animal studies}

Mostly conducted in rodents, these show varying degrees of beneficial effects of the neuronal implants on the motor symptoms generated by the experimentally-induced nigrostriatal lesion. A detailed description of these experiences can be found elsewhere. ${ }^{137,157,158}$

\section{Clinical data}

Various clinical trials have been conducted in PD patients, with controversial results. In early open-label trials, PD patients were transplanted into the caudate-putamen with either embryonic or fetal mesencephalic cells containing dopaminergic neurons. ${ }^{158-161}$ The procedure induced, in general, moderate amelioration of bradykinesia and rigidity, with minor effects on tremor, ${ }^{159,161,162}$ better response to L-DOPA was also reported, which allowed reduction of the daily drug intake. ${ }^{160}$ These encouraging results, however, were not confirmed by two NIH-sponsored, double-blind, placebo-controlled trials. ${ }^{163,164}$ In the work of Freed et al, ${ }^{163}$ patients were randomized to receive an intra-putaminal transplant of human embryonic dopamine neurons or sham surgery; they were followed in a double-blind manner for one year, post-surgery, the primary outcome being a subjective rating of the change in the severity of disease. No differences were found, between grafted and shamoperated patients, although PET examinations showed that fluorodopa uptake was increased in graft recipients. The only positive observation of the study was that younger patients tended to respond better to the grafting, compared to older patients. In the study conducted by the group of Olanow, ${ }^{164}$ patients were randomized to receive intraputaminal grafting of fetal nigral cells or sham surgery and were followed for 2 years; in this case, the primary end point was change of the motor UPDRS score between baseline and final visits. Again, no significant effects of the grafting procedure were observed, while striatal fluorodopa uptake was increased after transplantation; robust survival of dopamine neurons was observed in four patients who died of causes unrelated to the surgery. An additional problem related to the grafting procedure, which had already emerged in the study of Defer et al, ${ }^{159}$ was the occurrence of dyskinesia in transplanted patients. As confirmed by the these two large trials, ${ }^{163,164}$ as well as by the study of Hagell and collaborators, ${ }^{165}$ it became apparent that a considerable percentage (varying between 15 and $56 \%$ ) of PD patients develop dyskinetic movements, following transplantation, which persist after L-DOPA withdrawal. This discovery, coupled with the doubts raised on the actual symptomatic efficacy of the procedure, drastically reduced the interest of the scientific community in clinical grafting trials for PD.

Intense debate of this issue has been further stirred by recent reports on the post-mortem investigation of patients transplanted, more than a decade before, with fetal mesencephalic tissue. ${ }^{166,167}$ The reports showed the presence, in the transplanted tissue, of alpha-synuclein-positive LBs, suggesting that PD pathology might propagate from host to graft. The mechanisms underlying this propagation are unknown and currently under investigation; a first clue has been provided, very recently, by Desplats et al, ${ }^{168}$ who showed that alpha-synuclein can be "transmitted", via endocytosis, to neighboring neurons and neuronal precursor cells - both in vitro and in vivo - thereby producing LB-like inclusions.

\section{Stem cells}

As a consequence of the doubts raised on fetal tissue transplantation, researchers of the PD field began to explore the regenerative potential of pluripotent stem cells, as an innovative source of transplantable cells, to develop therapeutic strategies aimed at modifying the course of the disease. So far, no clinical trials have been conducted in PD patients. However, numerous studies have been carried out in animal PD models, which have generated encouraging, but sometimes controversial, results. Embryonic stem (ES) cells, for example, proved able to differentiate into dopaminergic neurons after transplantation into the striatum of rats lesioned with 6-OHDA ${ }^{169,170}$ or of monkeys intoxicated with MPTP, ${ }^{171}$ 
and to improve - although partially - motor abnormalities associated with the nigrostriatal lesion. More ambiguous findings have been obtained with neural stem cells, derived from adult or fetal brain, which tend to differentiate into astroglial cells rather than into dopamine neurons. ${ }^{172}$

In general, the degree of dopamine cell survival following transplantation is small and the magnitude of the behavioral benefit is modest. Various techniques have been used to improve the rate of pre-grafting differentiation of ES cells into post-mitotic, dopaminergic cells; for a comprehensive overview of this topic the reader can refer to a recent review. ${ }^{173}$ For the purpose of this article, however, a few techniques are worth mentioning. Zeng et al, ${ }^{174}$ for example, showed a $87 \%$ rate of differentiation into $\mathrm{TH}$-positive (dopaminergic) neurons when human ES cells were co-cultured with stromal cell line PA6. Following transplantation into 6-OHDAtreated animals, ES-derived dopaminergic cells integrated into the rat striatum, but, 5 weeks after transplantation, the number of surviving TH-positive cells was very small, compared with the frequency of those seen in vitro. Roy et al ${ }^{175}$ co-cultured human ES cells with telomerase-immortalized human fetal midbrain astrocytes, which potentiated differentiation toward the dopaminergic phenotype, particularly the A9, nigrostriatal phenotype. Striatal transplantation into 6-OHDA-lesioned rats induced substantial amelioration of motor functions. However, in addition to the ES-derived, TH-positive cells, the authors reported expanding cores of undifferentiated, mitotic neuroepithelial cells, indicating the tumorigenic potential of the graft. Satisfactory rates of in vitro differentiation have also been obtained by sequential exposure of embryoid bodies (ES aggregates) to basic fibroblast growth factor and transforming growth factor alpha. ${ }^{176}$

Due to ethical concerns and limited tissue availability, which tend to limit the potential of the human ES-based approach, alternative routes have been tried. Adult, bone-marrow-derived mesenchymal stem cells (MSCs), for example, have been recently proposed, ${ }^{177}$ as a promising alternative. The possible autologous derivation of MSCs avoids the immunological or ethical concerns related to other sources; another considerable advantage is that MSCs seem devoid of oncogenic potential; ${ }^{178} \mathrm{hMSCs}$ have differentiative multilineage capacity, which also includes the ability to differentiate toward the dopaminergic phenotype, at least in vitro. ${ }^{179}$ Moreover, hMSCs posses immunoregulatory properties, which are exerted through the release of soluble factors. ${ }^{180}$ These cells may, therefore, have the capacity of modulating the inflammatory response associated with the neurodegenerative process that underlies PD. Transplantation of
MSCs - of either human or rodent origin - into the striatum of rats lesioned with 6-OHDA exerts protective and/or regenerative effects on nigrostriatal neurons. ${ }^{181-183}$ The group of Bouchez, ${ }^{181}$ in particular, showed that hMSCs can promote neuronal survival also if grafted after inducing the nigrostriatal lesion. Similar results have been reported by Park et al, ${ }^{184}$ who administered hMSCs, iv, to rats treated, several weeks before, with a proteasome inhibitor. Proteasomal inhibition was associated with a substantial loss of TH-positive neurons in the SNpc, which was markedly reduced in rats infused with hMSCs; moreover, the low immunogenicity of MSCs ${ }^{185}$ made immunosuppressant treatment unnecessary. It can be concluded that transplantation of hMSCs counteracts the progressive degeneration of the nigrostriatal pathway caused by specific neurotoxins, even when the neurodegenerative process has already been set in motion and has reached a medium/advanced stage, thereby supporting the neuroregenerative potential of hMSCs.

Another approach, prompted by the open issue of the tumorigenic potential of pluripotent stem cells, is based on the use of xenographic transplants. In fact, there is evidence that ES cells are more likely to generate tumors when transplanted into the same species from which they were derived. ${ }^{186}$ Following this line of reasoning, Harrower et al ${ }^{187}$ transplanted porcine, cortically derived neural stem cells into the striatum of 6-OHDA lesioned rats. They found that grafts integrated and survived up to 5 months, with the formation of fibers extending into the striatal tissue and synapses.

Finally, fascinating perspectives in the field of neuroregenerative medicine have been recently provided by the studies on genetic reprogramming of adult somatic cells, such as dermal fibroblasts, to derive induced pluripotent stem (iPS) cells. Human fibroblasts, isolated from skin biopsies, can be reverted to the state of embryonic-like, iPS cells following transfection with retroviral vectors expressing a combination of 4 transcription factors (Oct4, Sox2, Klf4, c-Myc, or Oct4, Sox2, Nanog, Lin28), ${ }^{188,189}$ thereby providing an autologous source for cell replacement; once reverted to the pluripotent state, iPS cells can be differentiated into dopaminergic neurons. Using this approach, Wernig et al ${ }^{190}$ demonstrated that striatal transplantation of dopaminergic neurons derived from reprogrammed fibroblasts improve behavioural symptoms of rats bearing a 6-OHDA induced lesion of the nigrostriatal pathway. Very recently, to avoid the oncogenic risk linked to the stable integration of vectors in the genome of reprogrammed cells, Kaji et al ${ }^{191}$ have proposed a modification of the technique, by which iPS cells are generated from fibroblasts with a virus-free protocol, followed by excision 
of reprogramming factors. Using a virus-free reprogramming technique on fibroblasts of PD patients, Soldner et al have recently derived iPS cells, which have been subsequently differentiated into dopaminergic neurons. ${ }^{192}$

\section{Conclusions}

From what has been discussed, it appears that although neuroprotective properties have been attributed to various compounds already available in the pharmacological armamentarium of the neurologist, convincing evidence has been provided so far only for rasagiline $(1 \mathrm{mg})$. In fact, the argument on the neuroprotective effects of dopamine agonists remains controversial and may benefit from a re-evaluation of these compounds, based on the delayed start clinical trial design.

For a true neurorestorative intervention, promising perspectives are provided by the use of neurotrophic factors and/or stem cells (possibly of autologous origin), which, however, still need to unveil their full potential.

\section{Disclosure}

The author discloses no conflicts of interest.

\section{References}

1. de Rijk MC, Tzourio C, Breteler MM, et al. Prevalence of parkinsonism and Parkinson's disease in Europe: the EUROPARKINSON Collaborative Study. European Community Concerted Action on the Epidemiology of Parkinson's disease. J Neurol Neurosurg Psychiatry. 1997;62(1):10-15.

2. O'Brien JA, Alvarez P, Pitoniak-Morse C, Michels S, Tzivelekis S, Ward A. Annual cost of Parkinson's disease in the United States. Mov Dis. 2008;23(S1):S337.

3. Betarbet R, Sherer TB, Di Monte DA, Greenamyre JT. Mechanistic approaches to Parkinson's disease pathogenesis. Brain Pathol. 2002; 12(4):499-510.

4. Olanow CW. The pathogenesis of cell death in Parkinson's disease 2007. Mov Disord. 2007;22 Suppl 17:S335-S342.

5. Blandini F, Nappi G, Tassorelli C, Martignoni E. Functional changes of the basal ganglia circuitry in Parkinson's disease. Prog Neurobiol. 2000;62(1):63-88.

6. Jellinger KA. Pathology of Parkinson's disease. Changes other than the nigrostriatal pathway. Mol Chem Neuropathol. 1991;14(3):153-197.

7. Poewe W. Non-motor symptoms in Parkinson's disease. Eur J Neurol. 2008;15 Suppl 1:14-20.

8. Harrower TP, Michell AW, Barker RA. Lewy bodies in Parkinson's disease: protectors or perpetrators? Exp Neurol. 2005;195(1):1-6.

9. Schapira AH. Etiology of Parkinson's disease. Neurology. 2006; 66(10 Suppl 4):S10-S23.

10. Petrucelli L, Dawson TM. Mechanism of neurodegenerative disease: role of the ubiquitin proteasome system. Ann Med. 2004;36(4):315-320.

11. Smith PF. Inflammation in Parkinson's disease: an update. Curr Opin Investig Drugs. 2008;9(5):478-484.

12. Hirsch EC, Hunot S, Hartmann A. Neuroinflammatory processes in Parkinson's disease. Parkinsonism Relat Disord. 2005;11 Suppl 1:S9-S15.

13. Tatton WG, Chalmers-Redman R, Brown D, Tatton N. Apoptosis in Parkinson's disease: signals for neuronal degradation. Ann Neurol. 2003;53 Supp1 3:S61-S70.
14. Van Cruchten S, Van Den BW. Morphological and biochemical aspects of apoptosis, oncosis and necrosis. Anat Histol Embryol. 2002;31(4):214-223.

15. Hartley A, Stone JM, Heron C, Cooper JM, Schapira AH. Complex I inhibitors induce dose-dependent apoptosis in PC12 cells: relevance to Parkinson's disease. J Neurochem. 1994;63(5):1987-1990.

16. Zhang J, Price JO, Graham DG, Montine TJ. Secondary excitotoxicity contributes to dopamine-induced apoptosis of dopaminergic neuronal cultures. Biochem Biophys Res Commun. 1998;248(3):812-816.

17. Fornai F, Lenzi P, Gesi M, et al. Fine structure and biochemical mechanisms underlying nigrostriatal inclusions and cell death after proteasome inhibition. J Neurosci. 2003;23(26):8955-8966.

18. Lang-Rollin I, Vekrellis K, Wang Q, Rideout HJ, Stefanis L. Application of proteasomal inhibitors to mouse sympathetic neurons activates the intrinsic apoptotic pathway. J Neurochem. 2004;90(6):1511-1520.

19. Mochizuki H, Goto K, Mori H, Mizuno Y. Histochemical detection of apoptosis in Parkinson's disease. J Neurol Sci. 1996;137(2):120-123.

20. Anglade P, Vyas S, Javoy-Agid F, et al. Apoptosis and autophagy in nigral neurons of patients with Parkinson's disease. Histol Histopathol. 1997;12(1):25-31.

21. Hartmann A, Hunot S, Michel PP, et al. Caspase-3: A vulnerability factor and final effector in apoptotic death of dopaminergic neurons in Parkinson's disease. Proc Natl Acad Sci U S A. 2000;97(6):2875-2880.

22. Hartmann A, Troadec JD, Hunot S, et al. Caspase- 8 is an effector in apoptotic death of dopaminergic neurons in Parkinson's disease, but pathway inhibition results in neuronal necrosis. J Neurosci. 2001;21(7):2247-2255.

23. Mogi M, Togari A, Kondo T, et al. Caspase activities and tumor necrosis factor receptor R1 (p55) level are elevated in the substantia nigra from parkinsonian brain. J Neural Transm. 2000;107(3):335-341.

24. Tatton NA. Increased caspase 3 and Bax immunoreactivity accompany nuclear GAPDH translocation and neuronal apoptosis in Parkinson's disease. Exp Neurol. 2000;166(1):29-43.

25. Marshall KA, Daniel SE, Cairns N, Jenner P, Halliwell B. Upregulation of the anti-apoptotic protein Bcl-2 may be an early event in neurodegeneration: studies on Parkinson's and incidental Lewy body disease. Biochem Biophys Res Commun. 1997;240(1):84-87.

26. Nagatsu T, Mogi M, Ichinose H, Togari A. Changes in cytokines and neurotrophins in Parkinson's disease. J Neural Transm Suppl. 2000; (60):277-290.

27. Blandini F, Sinforiani E, Pacchetti C, et al. Peripheral proteasome and caspase activity in Parkinson disease and Alzheimer disease. Neurology. 2006;66(4):529-534.

28. Migliore L, Petrozzi L, Lucetti C, et al. Oxidative damage and cytogenetic analysis in leukocytes of Parkinson's disease patients. Neurology. 2002;58(12):1809-1815.

29. Blandini F, Cosentino M, Mangiagalli A, et al. Modifications of apoptosis-related protein levels in lymphocytes of patients with Parkinson's disease. The effect of dopaminergic treatment. $J$ Neural Transm. 2004;111(8):1017-1030.

30. Blum D, Torch S, Lambeng N, et al. Molecular pathways involved in the neurotoxicity of 6-OHDA, dopamine and MPTP: contribution to the apoptotic theory in Parkinson's disease. Prog Neurobiol. 2001;65(2):135-172.

31. Cotzias GC, Papavasiliou PS, Gellene R. Experimental treatment of parkinsonism with L-Dopa. Neurology. 1968;18(3):276-277.

32. Koller WC, Rueda MG. Mechanism of action of dopaminergic agents in Parkinson's disease. Neurology. 1998;50(6 Suppl 6):S11-S14.

33. Nutt JG, Woodward WR, Anderson JL. The effect of carbidopa on the pharmacokinetics of intravenously administered levodopa: the mechanism of action in the treatment of parkinsonism. Ann Neurol. 1985;18(5):537-543.

34. Obeso JA, Olanow CW, Nutt JG. Levodopa motor complications in Parkinson's disease. Trends Neurosci. 2000;23(10 Suppl):S2-S7.

35. Hely MA, Morris JG, Reid WG, et al. The Sydney Multicentre Study of Parkinson's disease: a randomised, prospective five year study comparing low dose bromocriptine with low dose levodopa-carbidopa. J Neurol Neurosurg Psychiatry. 1994;57(8):903-910. 
36. Poewe W, Gerstenbrand F. [Clinical subtypes of Parkinson disease]. Wien Med Wochenschr. 1986;136(15-16):384-387.

37. Limousin P, Pollak P, Benazzouz A, et al. Effect of parkinsonian signs and symptoms of bilateral subthalamic nucleus stimulation. Lancet. 1995;345(8942):91-95.

38. Benabid AL, Chabardes S, Mitrofanis J, Pollak P. Deep brain stimulation of the subthalamic nucleus for the treatment of Parkinson's disease. Lancet Neurol. 2009;8(1):67-81.

39. Schapira AH. Science, medicine, and the future: Parkinson's disease. BMJ. 1999;318(7179):311-314.

40. Schapira AH. Disease modification in Parkinson's disease. Lancet Neurol. 2004;3(6):362-368.

41. Melamed E, Offen D, Shirvan A, Djaldetti R, Barzilai A, Ziv I. Levodopa toxicity and apoptosis. Ann Neurol. 1998;44(3 Suppl 1): S149-S154.

42. Ziv I, Zilkha-Falb R, Offen D, Shirvan A, Barzilai A, Melamed E. Levodopa induces apoptosis in cultured neuronal cells - a possible accelerator of nigrostriatal degeneration in Parkinson's disease? Mov Disord. 1997;12(1):17-23.

43. Ahlskog JE, Uitti RJ, Low PA, Tyce GM, O’Brien JF, Nickander KK. Levodopa and deprenyl treatment effects on peripheral indices of oxidant stress in Parkinson's disease. Neurology. 1996;46(3):796-801.

44. Agil A, Duran R, Barrero F, et al. Plasma lipid peroxidation in sporadic Parkinson's disease. Role of the L-dopa. J Neurol Sci. 2006;240(1-2): 31-36.

45. Iacovitti L, Stull ND, Mishizen A. Neurotransmitters, $\mathrm{KCl}$ and antioxidants rescue striatal neurons from apoptotic cell death in culture. Brain Res. 1999;816(2):276-285.

46. Kondo T. Levodopa therapy from the neuroprotection viewpoint. From a clinical outlook. J Neurol. 2005;252 Suppl 4:IV32-IV36.

47. Prigione A, Begni B, Galbussera A, et al. Oxidative stress in peripheral blood mononuclear cells from patients with Parkinson's disease: negative correlation with levodopa dosage. Neurobiol Dis. 2006;23(1): 36-43.

48. Nair VD, Olanow CW, Sealfon SC. Activation of phosphoinositide 3-kinase by D2 receptor prevents apoptosis in dopaminergic cell lines. Biochem J. 2003;373(Pt 1):25-32.

49. Koh SH, Song C, Noh MY, et al. Inhibition of glycogen synthase kinase-3 reduces L-DOPA-induced neurotoxicity. Toxicology. 2008; 247(2-3):112-118.

50. Forde JE, Dale TC. Glycogen synthase kinase 3: a key regulator of cellular fate. Cell Mol Life Sci. 2007;64(15):1930-1944.

51. Fahn S. A new look at levodopa based on the ELLDOPA study. J Neural Transm Suppl. 2006;(70):419-426.

52. Fahn S. Parkinson disease, the effect of levodopa, and the ELLDOPA trial. Earlier vs Later L-DOPA. Arch Neurol. 1999;56(5):529-535.

53. Ahlskog JE. Slowing Parkinson's disease progression: recent dopamine agonist trials. Neurology. 2003;60(3):381-389.

54. Reichmann H. Initiation of Parkinson's disease treatment. J Neurol. 2008;255 Suppl 5:57-59.

55. Finotti N, Castagna L, Moretti A, Marzatico F. Reduction of lipid peroxidation in different rat brain areas after cabergoline treatment. Pharmacol Res. 2000;42(4):287-291.

56. Muralikrishnan D, Ebadi M. SKF-38393, a dopamine receptor agonist, attenuates 1-methyl-4-phenyl-1,2,3,6-tetrahydropyridine-induced neurotoxicity. Brain Res. 2001;892(2):241-247.

57. Yoshioka M, Tanaka K, Miyazaki I, et al. The dopamine agonist cabergoline provides neuroprotection by activation of the glutathione system and scavenging free radicals. Neurosci Res. 2002;43(3): 259-267.

58. Armentero MT, Fancellu R, Nappi G, Blandini F. Dopamine receptor agonists mediate neuroprotection in malonate-induced striatal lesion in the rat. Exp Neurol. 2002;178(2):301-305.

59. Asanuma M, Ogawa N, Nishibayashi S, Kawai M, Kondo Y, Iwata E. Protective effects of pergolide on dopamine levels in the 6-hydroxydopamine-lesioned mouse brain. Arch Int Pharmacodyn Ther. 1995;329(2):221-230.
60. Nishibayashi S, Asanuma M, Kohno M, Gomez-Vargas M, Ogawa N. Scavenging effects of dopamine agonists on nitric oxide radicals. J Neurochem. 1996;67(5):2208-2211.

61. Gu M, Iravani MM, Cooper JM, King D, Jenner P, Schapira AH. Pramipexole protects against apoptotic cell death by non-dopaminergic mechanisms. J Neurochem. 2004;91(5):1075-1081.

62. Kakimura J, Kitamura Y, Takata K, Kohno Y, Nomura Y, Taniguchi T. Release and aggregation of cytochrome $\mathrm{c}$ and alpha-synuclein are inhibited by the antiparkinsonian drugs, talipexole and pramipexole. Eur J Pharmacol. 2001;417(1-2):59-67.

63. Iravani MM, Haddon CO, Cooper JM, Jenner P, Schapira AH. Pramipexole protects against MPTP toxicity in non-human primates. J Neurochem. 2006;96(5):1315-1321.

64. Iravani MM, Sadeghian M, Leung CC, et al. Continuous subcutaneous infusion of pramipexole protects against lipopolysaccharide-induced dopaminergic cell death without affecting the inflammatory response. Exp Neurol. 2008;212(2):522-531.

65. Nair VD, Olanow CW. Differential modulation of Akt/glycogen synthase kinase-3beta pathway regulates apoptotic and cytoprotective signaling responses. J Biol Chem. 2008;283(22):15469-15478.

66. Du F, Li R, Huang Y, Li X, Le W. Dopamine D3 receptor-preferring agonists induce neurotrophic effects on mesencephalic dopamine neurons. Eur J Neurosci. 2005;22(10):2422-2430.

67. Whone AL, Watts RL, Stoessl AJ, et al. Slower progression of Parkinson's disease with ropinirole versus levodopa: The REAL-PET study. Ann Neurol. 2003;54(1):93-101.

68. Parkinson Study Group. Dopamine transporter brain imaging to assess the effects of pramipexole vs levodopa on Parkinson disease progression. JAMA. 2002;287(13):1653-1661.

69. Parkinson Study Group. Long-term effect of initiating pramipexole vs levodopa in early Parkinson disease. Arch Neurol. 2009;66(5): 563-570.

70. Youdim MB, Riederer PF. A review of the mechanisms and role of monoamine oxidase inhibitors in Parkinson's disease. Neurology. 2004;63(7 Suppl 2):S32-S35.

71. Riederer P, Lachenmayer L, Laux G. Clinical applications of MAOinhibitors. Curr Med Chem. 2004;11(15):2033-2043.

72. Jenner P. Oxidative stress in Parkinson's disease. Ann Neurol. 2003; 53 Suppl 3:S26-S36.

73. Markey SP, Schmuff NR. The pharmacology of the parkinsonian syndrome producing neurotoxin MPTP (1-methyl-4-phenyl-1,2,3, 6-tetrahydropyridine) and structurally related compounds. Med Res Rev. 1986;6(4):389-429.

74. Tatton WG, Greenwood CE. Rescue of dying neurons: a new action for deprenyl in MPTP parkinsonism. J Neurosci Res. 1991;30(4):666-672.

75. Tatton WG, Wadia JS, Ju WY, Chalmers-Redman RM, Tatton NA. (-)-Deprenyl reduces neuronal apoptosis and facilitates neuronal outgrowth by altering protein synthesis without inhibiting monoamine oxidase. J Neural Transm Suppl. 1996;48:45-59.

76. Tatton WG, Chalmers-Redman RM. Modulation of gene expression rather than monoamine oxidase inhibition: (-)-deprenyl-related compounds in controlling neurodegeneration. Neurology. 1996;47(6 Suppl 3): S171-S183.

77. Wu RM, Chen RC, Chiueh CC. Effect of MAO-B inhibitors on MPP+ toxicity in vivo. Ann N Y Acad Sci. 2000;899:255-261.

78. Parkinson Study Group. DATATOP: a multicenter controlled clinical trial in early Parkinson's disease. Arch Neurol. 1989;46(10):1052-1060.

79. Parkinson Study Group. Effects of tocopherol and deprenyl on the progression of disability in early Parkinson's disease. N Engl J Med. 1993;328(3):176-183.

80. LeWitt PA. Clinical trials of neuroprotection for Parkinson's disease. Neurology. 2004;63(7 Suppl 2):S23-S31.

81. LeWitt PA, Taylor DC. Protection against Parkinson's disease progression: clinical experience. Neurotherapeutics. 2008;5(2):210-225.

82. Reynolds GP, Elsworth JD, Blau K, Sandler M, Lees AJ, Stern GM. Deprenyl is metabolized to methamphetamine and amphetamine in man. Br J Clin Pharmacol. 1978;6(6):542-544. 
83. Oh C, Murray B, Bhattacharya N, Holland D, Tatton WG. (-)-Deprenyl alters the survival of adult murine facial motoneurons after axotomy: increases in vulnerable C57BL strain but decreases in motor neuron degeneration mutants. J Neurosci Res. 1994;38(1):64-74.

84. Abu-Raya S, Tabakman R, Blaugrund E, Trembovler V, Lazarovici P. Neuroprotective and neurotoxic effects of monoamine oxidase-B inhibitors and derived metabolites under ischemia in PC12 cells. Eur J Pharmacol. 2002;434(3):109-116.

85. Am OB, Amit T, Youdim MB. Contrasting neuroprotective and neurotoxic actions of respective metabolites of anti-Parkinson drugs rasagiline and selegiline. Neurosci Lett. 2004;355(3):169-172.

86. Olanow CW, Hauser RA, Gauger L, et al. The effect of deprenyl and levodopa on the progression of Parkinson's disease. Ann Neurol. 1995;38(5):771-777.

87. Finberg JP, Youdim MB. Pharmacological properties of the antiParkinson drug rasagiline; modification of endogenous brain amines, reserpine reversal, serotonergic and dopaminergic behaviours. Neuropharmacology. 2002;43(7):1110-1118.

88. Youdim MB, Gross A, Finberg JP. Rasagiline [N-propargyl-1R(+)aminoindan], a selective and potent inhibitor of mitochondrial monoamine oxidase B. Br J Pharmacol. 2001;132(2):500-506.

89. Maruyama W, Akao Y, Youdim MB, Naoi M. Neurotoxins induce apoptosis in dopamine neurons: protection by N-propargylamine1(R)- and (S)-aminoindan, rasagiline and TV1022. J Neural Transm Suppl. 2000;(60):171-186.

90. Maruyama W, Youdim MB, Naoi M. Antiapoptotic properties of rasagiline, N-propargylamine-1(R)-aminoindan, and its optical (S)-isomer, TV1022. Ann N Y Acad Sci. 2001;939:320-329.

91. Abu-Raya S, Blaugrund E, Trembovler V, Shilderman-Bloch E, Shohami E, Lazarovici P. Rasagiline, a monoamine oxidase-B inhibitor, protects NGF-differentiated PC12 cells against oxygen-glucose deprivation. J Neurosci Res. 1999;58(3):456-463.

92. Weinreb O, Bar-Am O, Amit T, Chillag-Talmor O, Youdim MB. Neuroprotection via pro-survival protein kinase $\mathrm{C}$ isoforms associated with Bcl-2 family members. FASEB J. 2004;18(12):1471-1473.

93. Youdim MB, Weinstock M. Molecular basis of neuroprotective activities of rasagiline and the anti-Alzheimer drug TV3326 [(N-propargyl-(3R)aminoindan-5-YL)-ethyl methyl carbamate]. Cell Mol Neurobiol. 2001;21(6):555-573.

94. Maruyama W, Akao Y, Carrillo MC, Kitani K, Youdium MB, Naoi M. Neuroprotection by propargylamines in Parkinson's disease: suppression of apoptosis and induction of prosurvival genes. Neurotoxicol Teratol. 2002;24(5):675-682.

95. Akao Y, Maruyama W, Shimizu S, et al. Mitochondrial permeability transition mediates apoptosis induced by $\mathrm{N}$-methyl(R)salsolinol, an endogenous neurotoxin, and is inhibited by Bcl-2 and rasagiline, N-propargyl-1(R)-aminoindan. J Neurochem. 2002;82(4):913-923.

96. Naoi M, Maruyama W, Akao Y, Yi H. Mitochondria determine the survival and death in apoptosis by an endogenous neurotoxin $\mathrm{N}$-methyl(R)salsolinol, and neuroprotection by propargylamines. J Neural Transm. 2002;109(5-6):607-621.

97. Youdim MB, Amit T, Falach-Yogev M, Am OB, Maruyama W, Naoi M. The essentiality of Bcl-2, PKC and proteasome-ubiquitin complex activations in the neuroprotective-antiapoptotic action of the anti-Parkinson drug, rasagiline. Biochem Pharmacol. 2003;66(8): 1635-1641.

98. Durkin JP, Tremblay R, Chakravarthy B, et al. Evidence that the early loss of membrane protein kinase $\mathrm{C}$ is a necessary step in the excitatory amino acid-induced death of primary cortical neurons. $J$ Neurochem 1997;68(4):1400-1412.

99. Maher P. How protein kinase $\mathrm{C}$ activation protects nerve cells from oxidative stress-induced cell death. J Neurosci. 2001;21(9):2929-2938.

100. Maruyama W, Nitta A, Shamoto-Nagai M, et al. N-Propargyl-1 (R)-aminoindan, rasagiline, increases glial cell line-derived neurotrophic factor (GDNF) in neuroblastoma SH-SY5Y cells through activation of NF-kappaB transcription factor. Neurochem Int. 2004; 44(6):393-400.
101. Youdim MB, Wadia A, Tatton W, Weinstock M. The anti-Parkinson drug rasagiline and its cholinesterase inhibitor derivatives exert neuroprotection unrelated to MAO inhibition in cell culture and in vivo. Ann N Y Acad Sci. 2001;939:450-458.

102. Blandini F, Armentero MT, Fancellu R, Blaugrund E, Nappi G. Neuroprotective effect of rasagiline in a rodent model of Parkinson's disease. Exp Neurol. 2004;187(2):455-459.

103. Kupsch A, Sautter J, Gotz ME, et al. Monoamine oxidase-inhibition and MPTP-induced neurotoxicity in the non-human primate: comparison of rasagiline (TVP 1012) with selegiline. J Neural Transm. 2001;108(8-9):985-1009.

104. Rabey JM, Sagi I, Huberman M, et al. Rasagiline mesylate, a new MAO-B inhibitor for the treatment of Parkinson's disease: a doubleblind study as adjunctive therapy to levodopa. Clin Neuropharmacol. 2000;23(6):324-330.

105. Stern MB, Marek KL, Friedman J, et al. Double-blind, randomized, controlled trial of rasagiline as monotherapy in early Parkinson's disease patients. Mov Disord. 2004;19(8):916-923.

106. Parkinson Study Group. A controlled trial of rasagiline in early Parkinson disease: the TEMPO Study. Arch Neurol. 2002;59(12):1937-1943.

107. Parkinson Study Group. A controlled, randomized, delayed-start study of rasagiline in early Parkinson disease. Arch Neurol. 2004;61(4): 561-566.

108. Hauser RA, Lew MF, Hurtig HI, Ondo WG, Wojcieszek J, FitzerAttas CJ. Long-term outcome of early versus delayed rasagiline treatment in early Parkinson's disease. Mov Disord. 2009;24(4):564-573.

109. Olanow CW, Hauser RA, Jankovic J, et al. A randomized, doubleblind, placebo-controlled, delayed start study to assess rasagiline as a disease modifying therapy in Parkinson's disease (the ADAGIO study): rationale, design, and baseline characteristics. Mov Disord. 2008;23(15):2194-2201.

110. Olanow CW, Rascol O. Early rasagiline treatment slows UPDRS decline in the ADAGIO delayed start study. Ann Neurol. 2008; 64(Suppl 12):S68.

111. Lindvall O, Rehncrona S, Brundin P, et al. Human fetal dopamine neurons grafted into the striatum in two patients with severe Parkinson's disease. A detailed account of methodology and a 6-month follow-up. Arch Neurol. 1989;46(6):615-631.

112. Lindvall O. Transplants in Parkinson's disease. Eur Neurol. 1991; 31 Suppl 1:17-27.

113. Ventrella LL. Effect of intracerebroventricular infusion of epidermal growth factor in rats hemitransected in the nigro-striatal pathway. J Neurosurg Sci. 1993;37(1):1-8.

114. de Yebenes JG, Pernaute RS, Garrido JM, et al. Long-term intracerebral infusion of fibroblast growth factors restores motility and enhances F-DOPA uptake in parkinsonian monkeys. Parkinsonism Relat Disord. 1998;4(3):147-158.

115. Hoffer B, Olson L. Treatment strategies for neurodegenerative diseases based on trophic factors and cell transplantation techniques J Neural Transm Suppl. 1997;49:1-10.

116. Pearce RK, Collins P, Jenner P, Emmett C, Marsden CD. Intraventricular infusion of basic fibroblast growth factor (bFGF) in the MPTPtreated common marmoset. Synapse. 1996;23(3):192-200.

117. Shults CW, Ray J, Tsuboi K, Gage FH. Fibroblast growth factor-2producing fibroblasts protect the nigrostriatal dopaminergic system from 6-hydroxydopamine. Brain Res. 2000;883(2):192-204.

118. Svendsen CN, Clarke DJ, Rosser AE, Dunnett SB. Survival and differentiation of rat and human epidermal growth factor-responsive precursor cells following grafting into the lesioned adult central nervous system. Exp Neurol. 1996;137(2):376-388.

119. Cass WA, Peters LE, Harned ME, Seroogy KB. Protection by GDNF and other trophic factors against the dopamine-depleting effects of neurotoxic doses of methamphetamine. Ann N Y Acad Sci. 2006;1074:272-281.

120. Hyman C, Hofer M, Barde YA, et al. BDNF is a neurotrophic factor for dopaminergic neurons of the substantia nigra. Nature. 1991;350(6315):230-232. 
121. Lucidi-Phillipi CA, Gage FH, Shults CW, Jones KR, Reichardt LF, Kang UJ. Brain-derived neurotrophic factor-transduced fibroblasts: production of BDNF and effects of grafting to the adult rat brain. J Comp Neurol. 1995;354(3):361-376.

122. Sauer H, Rosenblad C, Bjorklund A. Glial cell line-derived neurotrophic factor but not transforming growth factor beta 3 prevents delayed degeneration of nigral dopaminergic neurons following striatal 6-hydroxydopamine lesion. Proc Natl Acad Sci U S A. 1995; 92(19):8935-8939.

123. Tomac A, Lindqvist E, Lin LF, et al. Protection and repair of the nigrostriatal dopaminergic system by GDNF in vivo. Nature. 1995; 373(6512):335-339.

124. Aoi M, Date I, Tomita S, Ohmoto T. The effect of intrastriatal single injection of GDNF on the nigrostriatal dopaminergic system in hemiparkinsonian rats: behavioral and histological studies using two different dosages. Neurosci Res. 2000;36(4):319-325.

125. Boger HA, Middaugh LD, Zaman V, Hoffer B, Granholm AC. Differential effects of the dopamine neurotoxin MPTP in animals with a partial deletion of the GDNF receptor, GFR alpha1, gene. Brain Res. 2008;1241:18-28.

126. Burke RE, Antonelli M, Sulzer D. Glial cell line-derived neurotrophic growth factor inhibits apoptotic death of postnatal substantia nigra dopamine neurons in primary culture. $J$ Neurochem. 1998;71(2):517-525.

127. Choi-Lundberg DL, Bohn MC. Ontogeny and distribution of glial cell line-derived neurotrophic factor (GDNF) mRNA in rat. Brain Res Dev Brain Res. 1995;85(1):80-88.

128. Barroso-Chinea P, Cruz-Muros I, Aymerich MS, et al. Striatal expression of GDNF and differential vulnerability of midbrain dopaminergic cells. Eur J Neurosci. 2005;21(7):1815-1827.

129. Gouhier C, Chalon S, Venier-Julienne MC, et al. Neuroprotection of nerve growth factor-loaded microspheres on the D2 dopaminergic receptor positive-striatal neurones in quinolinic acid-lesioned rats: a quantitative autoradiographic assessment with iodobenzamide. Neurosci Lett. 2000;288(1):71-75.

130. Menei P, Pean JM, Nerriere-Daguin V, Jollivet C, Brachet P, Benoit JP. Intracerebral implantation of NGF-releasing biodegradable microspheres protects striatum against excitotoxic damage. Exp Neurol. 2000;161(1):259-272.

131. Aubert-Pouessel A, Venier-Julienne MC, Clavreul A, et al. In vitro study of GDNF release from biodegradable PLGA microspheres. J Control Release. 2004;95(3):463-475.

132. Gouhier C, Chalon S, Aubert-Pouessel A, et al. Protection of dopaminergic nigrostriatal afferents by GDNF delivered by microspheres in a rodent model of Parkinson's disease. Synapse. 2002; 44(3):124-131.

133. Jollivet C, Aubert-Pouessel A, Clavreul A, et al. Striatal implantation of GDNF releasing biodegradable microspheres promotes recovery of motor function in a partial model of Parkinson's disease. Biomaterials. 2004;25(5):933-942.

134. Jollivet C, Aubert-Pouessel A, Clavreul A, et al. Long-term effect of intra-striatal glial cell line-derived neurotrophic factor-releasing microspheres in a partial rat model of Parkinson's disease. Neurosci Lett. 2004;356(3):207-210.

135. Garbayo E, Montero-Menei CN, Ansorena E, Lanciego JL, Aymerich MS, Blanco-Prieto MJ. Effective GDNF brain delivery using microspheres - a promising strategy for Parkinson's disease. J Control Release. 2009;135(2):119-126.

136. Dietz GP, Valbuena PC, Dietz B, et al. Application of a blood-brainbarrier-penetrating form of GDNF in a mouse model for Parkinson's disease. Brain Res. 2006;1082(1):61-66.

137. Deierborg T, Soulet D, Roybon L, Hall V, Brundin P. Emerging restorative treatments for Parkinson's disease. Prog Neurobiol. 2008;85(4):407-432.

138. Bensadoun JC, Deglon N, Tseng JL, Ridet JL, Zurn AD, Aebischer P. Lentiviral vectors as a gene delivery system in the mouse midbrain: cellular and behavioral improvements in a 6-OHDA model of Parkinson's disease using GDNF. Exp Neurol. 2000;164(1):15-24.
139. Brizard M, Carcenac C, Bemelmans AP, Feuerstein C, Mallet J, Savasta M. Functional reinnervation from remaining DA terminals induced by GDNF lentivirus in a rat model of early Parkinson's disease. Neurobiol Dis. 2006;21(1):90-101.

140. Deglon N, Tseng JL, Bensadoun JC, et al. Self-inactivating lentiviral vectors with enhanced transgene expression as potential gene transfer system in Parkinson's disease. Hum Gene Ther. 2000;11(1): 179-190.

141. Dowd E, Monville C, Torres EM, et al. Lentivector-mediated delivery of GDNF protects complex motor functions relevant to human Parkinsonism in a rat lesion model. Eur J Neurosci. 2005;22(10): 2587-2595.

142. Kordower JH, Emborg ME, Bloch J, et al. Neurodegeneration prevented by lentiviral vector delivery of GDNF in primate models of Parkinson's disease. Science. 2000;290(5492):767-773.

143. Kirik D, Georgievska B, Rosenblad C, Bjorklund A. Delayed infusion of GDNF promotes recovery of motor function in the partial lesion model of Parkinson's disease. Eur J Neurosci. 2001;13(8):1589-1599.

144. Wang L, Muramatsu S, Lu Y, et al. Delayed delivery of AAV-GDNF prevents nigral neurodegeneration and promotes functional recovery in a rat model of Parkinson's disease. Gene Ther. 2002;9(6):381-389.

145. Zheng JS, Tang LL, Zheng SS, et al. Delayed gene therapy of glial cell line-derived neurotrophic factor is efficacious in a rat model of Parkinson's disease. Brain Res Mol Brain Res. 2005;134(1):155-161.

146. Herzog CD, Brown L, Gammon D, et al. Expression, bioactivity, and safety 1 year after adeno-associated viral vector type 2-mediated delivery of neurturin to the monkey nigrostriatal system support cere-120 for Parkinson's disease. Neurosurgery. 2009;64(4):602-612.

147. Park KW, Eglitis MA, Mouradian MM. Protection of nigral neurons by GDNF-engineered marrow cell transplantation. Neurosci Res. 2001;40(4):315-323.

148. Akerud P, Canals JM, Snyder EY, Arenas E. Neuroprotection through delivery of glial cell line-derived neurotrophic factor by neural stem cells in a mouse model of Parkinson's disease. J Neurosci. 2001;21(20):8108-8118.

149. Cunningham LA, Su C. Astrocyte delivery of glial cell line-derived neurotrophic factor in a mouse model of Parkinson's disease. Exp Neurol. 2002;174(2):230-242.

150. Ericson C, Georgievska B, Lundberg C. Ex vivo gene delivery of GDNF using primary astrocytes transduced with a lentiviral vector provides neuroprotection in a rat model of Parkinson's disease. Eur J Neurosci. 2005;22(11):2755-2764.

151. Lindvall O, Wahlberg LU. Encapsulated cell biodelivery of GDNF: a novel clinical strategy for neuroprotection and neuroregeneration in Parkinson's disease? Exp Neurol. 2008;209(1):82-88.

152. Nutt JG, Burchiel KJ, Comella CL, et al. Randomized, double-blind trial of glial cell line-derived neurotrophic factor (GDNF) in PD. Neurology. 2003;60(1):69-73.

153. Gill SS, Patel NK, Hotton GR, et al. Direct brain infusion of glial cell line-derived neurotrophic factor in Parkinson disease. Nat Med. 2003;9(5):589-595.

154. Slevin JT, Gerhardt GA, Smith CD, Gash DM, Kryscio R, Young B. Improvement of bilateral motor functions in patients with Parkinson disease through the unilateral intraputaminal infusion of glial cell linederived neurotrophic factor. J Neurosurg. 2005;102(2):216-222.

155. Lang AE, Gill S, Patel NK, et al. Randomized controlled trial of intraputamenal glial cell line-derived neurotrophic factor infusion in Parkinson disease. Ann Neurol. 2006;59(3):459-466.

156. Marks WJ Jr, Ostrem JL, Verhagen L, et al. Safety and tolerability of intraputaminal delivery of CERE-120 (adeno-associated virus serotype 2-neurturin) to patients with idiopathic Parkinson's disease: an open-label, phase I trial. Lancet Neurol. 2008;7(5):400-408.

157. Winkler C, Kirik D, Bjorklund A, Dunnett SB. Transplantation in the rat model of Parkinson's disease: ectopic versus homotopic graft placement. Prog Brain Res. 2000;127:233-265.

158. Bjorklund A, Dunnett SB, Brundin P, et al. Neural transplantation for the treatment of Parkinson's disease. Lancet Neurol. 2003;2(7):437-445. 
159. Defer GL, Geny C, Ricolfi F, et al. Long-term outcome of unilaterally transplanted parkinsonian patients. I. Clinical approach. Brain. 1996;119(Pt 1):41-50.

160. Freed CR, Rosenberg NL, Schneck SA, Breeze RE. Improved drug responsiveness following fetal tissue implant for Parkinson's disease. Neurochem Int. 1992;(20 Suppl):321S-327S.

161. Freed CR, Breeze RE, Rosenberg NL, et al. Survival of implanted fetal dopamine cells and neurologic improvement 12 to 46 months after transplantation for Parkinson's disease. N Engl J Med. 1992; 327(22):1549-1555.

162. Brundin P, Pogarell O, Hagell P, et al. Bilateral caudate and putamen grafts of embryonic mesencephalic tissue treated with lazaroids in Parkinson's disease. Brain. 2000;123(Pt 7):1380-1390.

163. Freed CR, Greene PE, Breeze RE, et al. Transplantation of embryonic dopamine neurons for severe Parkinson's disease. $N$ Engl J Med. 2001;344(10):710-719.

164. Olanow CW, Goetz CG, Kordower JH, et al. A double-blind controlled trial of bilateral fetal nigral transplantation in Parkinson's disease. Ann Neurol. 2003;54(3):403-414.

165. Hagell P, Piccini P, Bjorklund A, et al. Dyskinesias following neural transplantation in Parkinson's disease. Nat Neurosci. 2002;5(7):627-628.

166. Kordower JH, Chu Y, Hauser RA, Freeman TB, Olanow CW. Lewy body-like pathology in long-term embryonic nigral transplants in Parkinson's disease. Nat Med. 2008;14(5):504-506.

167. Li JY, Englund E, Holton JL, et al. Lewy bodies in grafted neurons in subjects with Parkinson's disease suggest host-to-graft disease propagation. Nat Med. 2008;14(5):501-503.

168. Desplats P, Lee HJ, Bae EJ, et al. Inclusion formation and neuronal cell death through neuron-to-neuron transmission of $\{$ alpha $\}$-synuclein Proc Natl Acad Sci U S A. 2009.

169. Cho YH, Kim DS, Kim PG, et al. Dopamine neurons derived from embryonic stem cells efficiently induce behavioral recovery in a Parkinsonian rat model. Biochem Biophys Res Commun. 2006; 341(1):6-12.

170. Bjorklund LM, Isacson O. Regulation of dopamine cell type and transmitter function in fetal and stem cell transplantation for Parkinson's disease. Prog Brain Res. 2002;138:411-420.

171. Takahashi J, Takagi Y, Saiki H. Transplantation of embryonic stem cell-derived dopaminergic neurons in MPTP-treated monkeys. Methods Mol Biol. 2009;482:199-212.

172. Snyder BJ, Olanow CW. Stem cell treatment for Parkinson's disease: an update for 2005. Curr Opin Neurol. 2005;18(4):376-385.

173. Lindvall O, Kokaia Z. Prospects of stem cell therapy for replacing dopamine neurons in Parkinson's disease. Trends Pharmacol Sci. 2009;30(5):260-267.

174. Zeng X, Cai J, Chen J, et al. Dopaminergic differentiation of human embryonic stem cells. Stem Cells. 2004;22(6):925-940.

175. Roy NS, Cleren C, Singh SK, Yang L, Beal MF, Goldman SA. Functional engraftment of human ES cell-derived dopaminergic neurons enriched by coculture with telomerase-immortalized midbrain astrocytes. Nat Med. 2006;12(11):1259-1268.

176. Park S, Lee KS, Lee YJ, et al. Generation of dopaminergic neurons in vitro from human embryonic stem cells treated with neurotrophic factors. Neurosci Lett. 2004;359(1-2):99-103.
177. Giordano A, Galderisi U, Marino IR. From the laboratory bench to the patient's bedside: an update on clinical trials with mesenchymal stem cells. J Cell Physiol. 2007;211(1):27-35.

178. Choumerianou DM, Dimitriou H, Perdikogianni C, Martimianaki G, Riminucci M, Kalmanti M. Study of oncogenic transformation in ex vivo expanded mesenchymal cells, from paediatric bone marrow. Cell Prolif. 2008;41(6):909-922.

179. Kan I, Ben Zur T, Barhum Y, et al. Dopaminergic differentiation of human mesenchymal stem cells - utilization of bioassay for tyrosine hydroxylase expression. Neurosci Lett. 2007;419(1):28-33.

180. Krampera M, Cosmi L, Angeli R, et al. Role for interferongamma in the immunomodulatory activity of human bone marrow mesenchymal stem cells. Stem Cells. 2006;24(2):386-398.

181. Bouchez G, Sensebe L, Vourc'h P, et al. Partial recovery of dopaminergic pathway after graft of adult mesenchymal stem cells in a rat model of Parkinson's disease. Neurochem Int. 2008;52(7): 1332-1342.

182. Levy YS, Bahat-Stroomza M, Barzilay R, et al. Regenerative effect of neural-induced human mesenchymal stromal cells in rat models of Parkinson's disease. Cytotherapy. 2008;10(4):340-352.

183. Sadan O, Bahat-Stromza M, Barhum Y, et al. Protective effects of neurotrophic factors secreting cells in a 60HDA rat model of Parkinson disease. Stem Cells Dev. 2009.

184. Park HJ, Lee PH, Bang OY, Lee G, Ahn YH. Mesenchymal stem cells therapy exerts neuroprotection in a progressive animal model of Parkinson's disease. J Neurochem. 2008;107(1):141-151.

185. Barry FP, Murphy JM, English K, Mahon BP. Immunogenicity of adult mesenchymal stem cells: lessons from the fetal allograft. Stem Cells Dev. 2005;14(3):252-265.

186. Erdo F, Buhrle C, Blunk J, et al. Host-dependent tumorigenesis of embryonic stem cell transplantation in experimental stroke. J Cereb Blood Flow Metab. 2003;23(7):780-785.

187. Harrower TP, Tyers P, Hooks Y, Barker RA. Long-term survival and integration of porcine expanded neural precursor cell grafts in a rat model of Parkinson's disease. Exp Neurol. 2006;197(1): 56-69.

188. Park IH, Daley GQ. Human iPS cell derivation/reprogramming. Curr Protoc Stem Cell Biol. 2009; Chapter 4:Unit.

189. Lowry WE, Richter L, Yachechko R, et al. Generation of human induced pluripotent stem cells from dermal fibroblasts. Proc Natl Acad Sci U S A. 2008;105(8):2883-2888.

190. Wernig M, Zhao JP, Pruszak J, et al. Neurons derived from reprogrammed fibroblasts functionally integrate into the fetal brain and improve symptoms of rats with Parkinson's disease. Proc Natl Acad Sci U S A. 2008;105(15):5856-5861.

191. Kaji K, Norrby K, Paca A, Mileikovsky M, Mohseni P, Woltjen K. Virus-free induction of pluripotency and subsequent excision of reprogramming factors. Nature. 2009;458(7239):771-775.

192. Soldner F, Hockemeyer D, Beard C, et al. Parkinson's disease patientderived induced pluripotent stem cells free of viral reprogramming factors. Cell. 2009;136(5):964-977.
Open Access Journal of Clinical Trials

\section{Publish your work in this journal}

The Open Access Journal of Clinical Trials is an international, peerreviewed, open access journal publishing original research, reports, editorials, reviews and commentaries on all aspects of clinical tria design, management, legal, ethical and regulatory issues, case record form design, data collection, quality assurance and data auditing

\section{Dovepress}

methodologies. The manuscript management system is completely online and includes a very quick and fair peer-review system, which is all easy to use. Visit http://www.dovepress.com/testimonials.php to read real quotes from published authors. 